\title{
Literature Search on the Bioactive Components in Medicinal Plants Controlling Diabetes Mellitus
}

\section{S Bhuvaneswari ${ }^{1 *}$, MG Ragunathan ${ }^{2}$ and J Jayanthi ${ }^{3}$}

${ }^{1}$ Assistant Professor, Department of Advanced Zoology and Biotechnology, Guru

Nanak College, Chennai, India

${ }^{2}$ Principal, Guru Nanak College, Chennai, India

${ }^{3}$ Head of the Department, Department of Advanced Zoology and Biotechnology,

Guru Nanak College, Chennai, India

*Corresponding Author: S Bhuvaneswari, Assistant Professor, Department of

Advanced Zoology and Biotechnology, Guru Nanak College, Chennai, India.
Received: September 30, 2021

Published: November 16, 2021

(C) All rights are reserved by $\mathbf{S}$ Bhuvaneswari., et al.

\begin{abstract}
Extract of different parts of plants to cure various diseases have been practiced since ancient period. These extracts are been part of the primary source of medicine in rural areas of the developing countries. It is been estimated that about $80 \%$ of the population in developing countries use traditional medicines as the health care medications. Newer plant based medicines are in the process of development using suitable drug delivery system and subsequent preclinical and clinical trials using modern techniques.
\end{abstract}

Keywords: Diabetes Mellitus; Plants; Bioactive Components

\section{Introduction}

Plants possess medicinal value have been used to cure various diseases including Diabetics mellitus. Bioactive components present in various parts of the plants are extracted by different methods for controlling and preventing Diabetics mellitus. It is well proven that diabetes leads to blindness, amputation, renal failure and cardiac arrest or stroke. As, herbal medicines have very effective therapeutic properties and they possess comparatively less adverse effect than modern medicines, the use of herbal medicines has been increased all over the world. Herbal medicines are considered as one of the best alternative to modern medicines though there are available approaches to treat diabetes and its secondary complications. While selecting a herbal medicine to treat diabetes, few imperative factors are to be considered, which include the stage of progression of diabetes, types of co morbidities of patients, availability of herbal drugs, safety profile of herbal drugs and affordability. This literature reveals the role of various medicinal herbs for their hypoglycemic effect. Some of the important herbs are tabulated in table 1.

\section{Search criteria}

Peer reviewed articles having search terms diabetes mellitus, herbal medicines for diabetes, medicinal plant for diabetes, hypoglycemic herbs, insulin plants, insulin secretion and hyperglycemia. Searches were made on articles published in English in Google scholars, medline Iran medex, Irandoc, ISI, PubMed, Scopus, SID, Magiran and few other internet sources.

\section{Broad inclusion criteria}

A broad inclusion criteria was followed to select the literatures for the current review. These inclusion criteria include the search terms such as antidiabetic herbs, medicinal plant for diabetes. 


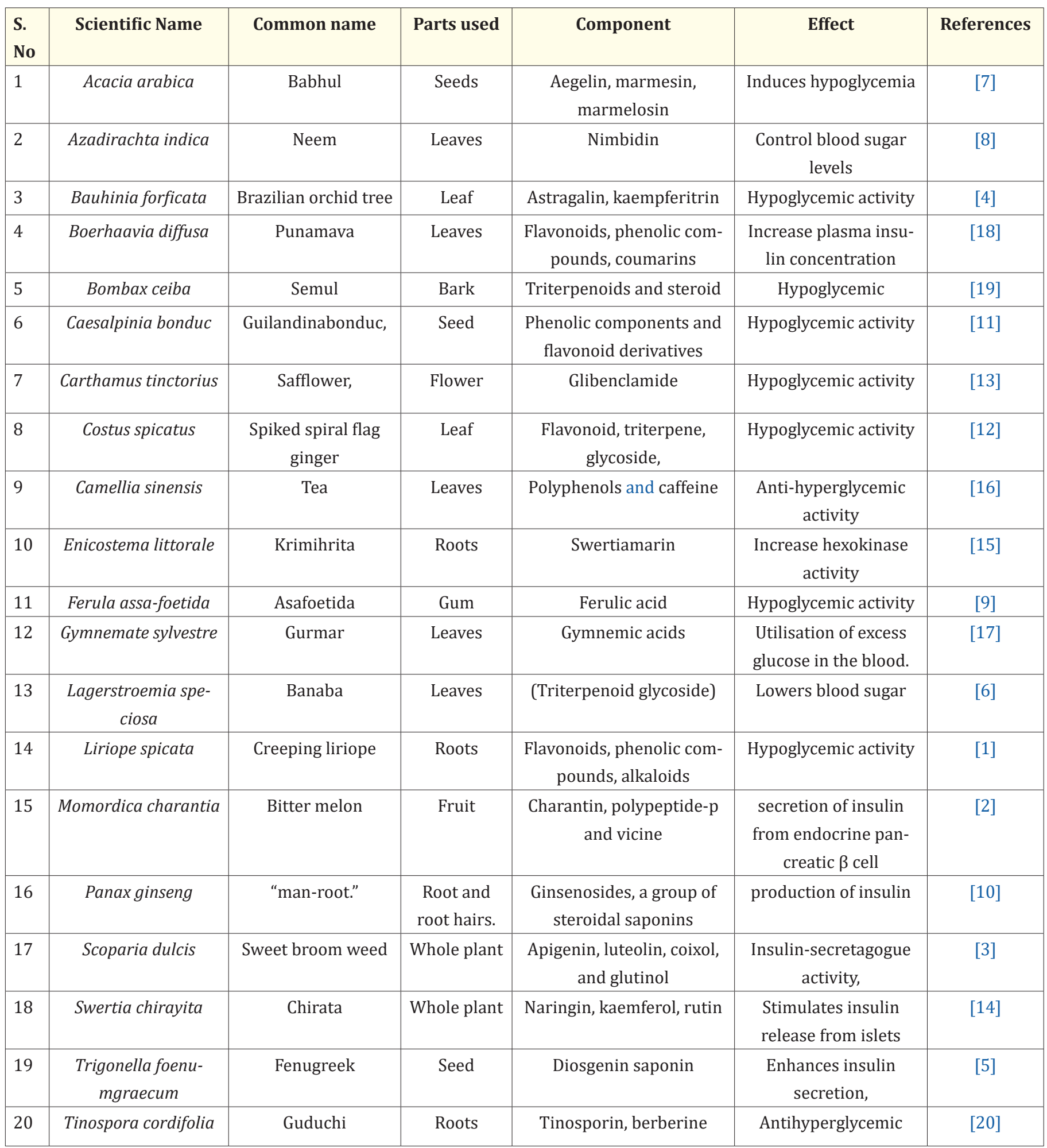

Table 1: Medicinal herbs and therapeutic information in Diabetes. 


\section{Narrow inclusion criteria}

Literatures that met the broad inclusion criteria were further reviewed for the refinement of data to narrow down the search data to more specific to the current study.

Flow chart detailing the process of literatures screened for the current review.

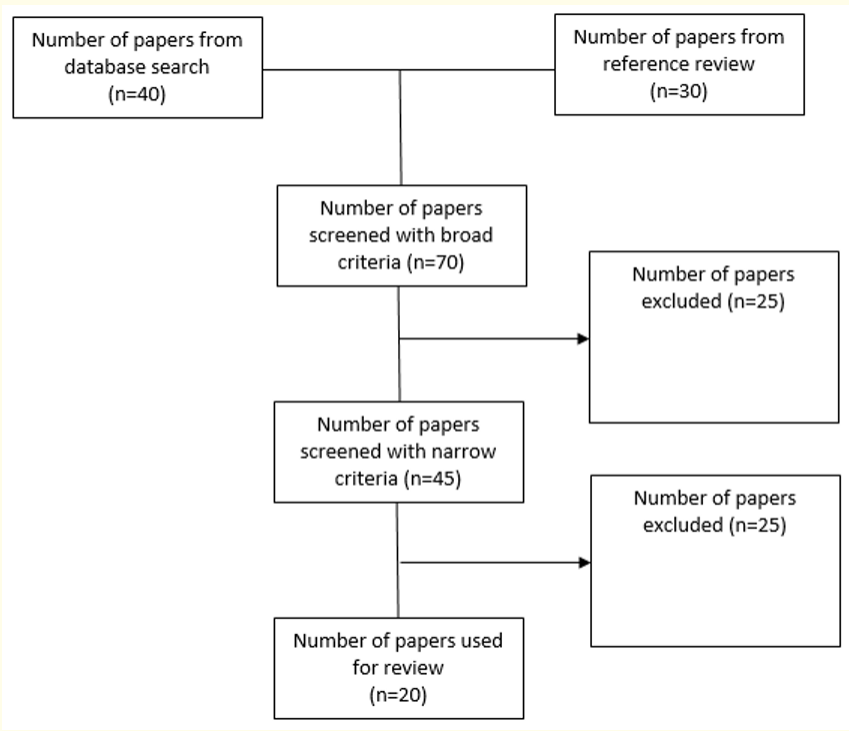

Flow Chart

\section{Conclusion}

The traditional knowledge such as pharmacological mechanism, side effects and curing effects of the medicinal plants opens up a new avenue in the modern society. The use of herbs having anti diabetic properties which leads to the well being of any diabetic patients is in growing pace. The usage of medicinal plants having hypoglycemic effects to treat diabetes mellitus and its secondary complications are of great concern in the current medicine system. It is essential to characterize the effects of various Bioactive compounds present in different herbs for their efficacy method of treatment. More clinical investigations and pharmacological studies need to be carried out to substantiate the anti diabetic and insulin mimetic activity of these medicinal plants.

\section{Acknowledgment}

The authors sincerely thank the unflinching support of Sardar Manjit Singh Nayar, General Secretary and Correspondent of Guru Nanak college, Chennai.

\section{Bibliography}

1. Patel DK., et al. "Pedalium murex Linn (Pedaliaceae) fruits: a comparative antioxidant activity of its different fractions". Asian Pacific Journal of Tropical Biomedicine 1.5 (2011): 395400.

2. Grover JK., et al. "Medicinal plants of India with anti-diabetic potential". Journal of Ethnopharmacology 81.1 (2002): 81-100.

3. Mustafa SSS., et al. "Insulinotropic effect of aqueous ginger extract and aqueous garlic extract on the isolated perfused pancreas of streptozotocin induced diabetic rats". Pakistan Journal of Zoology 39.5 (2007): 279-284.

4. Rao MU., et al. "Herbal medicines for diabetes mellitus: a review". International Journal of PharmTech Research 2.3 (2010): 1883-1892.

5. Haeri MR., et al. "The effect of fenugreek 4-hydroxyisoleucine on liver function biomarkers and glucose in diabetic and fructose-fed rats". Phytotherapy Research 23.1 (2009): 61-64.

6. Garcia F. "On the hypoglycemic effect of decoction of Lagerstroemia speciosa leaves (banaba) administered orally". Journal - Philippine Medical Association 20 (1940): 395-402.

7. Chowdhury AR., et al. "Chemical composition of Acacia seeds". Journal of the American Oil Chemists' Society 60 (1983): 18931894.

8. Satyanarayana MK., et al. "A preliminary study on hypoglycaemic and antihyperglycaemic effects of Azadirachta indica". Indian Journal of Pharmacology 10 (1978): 247-250.

9. Abu-Zaiton AS. "Anti-diabetic activity of Ferula assafoetida extract in normal and alloxan- induced diabetic rats". Pakistan Journal of Biological Sciences 13.2 (2010): 97-100.

10. Kimura M., et al. "Effects of hypoglycemic components in ginseng radix on blood insulin level in alloxan diabetic mice and on insulin release from perfused rat pancreas". Journal of Pharmacobio-Dynamics 4 (1981): 410 -417. 
11. Sharma SR., et al. "Hypoglycemia, anti hyperglycemic activity and hypoglycemic activity of Caesalpinia bonduc seeds and seeds in rats". Journal of Ethnopharmacology 58.1 (1997): 3944.

12. S. Bhuvaneswari, V.Umarani and S.Natarajan. "Analysis of Bioactive Components from the Ethanolic leaf extracts of Costus spicatus". International Journal of Natural Products Research.

13. Liu Y., et al. "Studies on chemical constituents from the flowers of Carthamustinctorius L". Zhong Yao Cai 28 (2005): 288-289.

14. Kumar KPS., et al. "Swertia chirata: A traditional herb and its medicinal uses". Journal of Chemical and Pharmaceutical Research 2 (2010): 262-266.

15. Upadhyay UM and Goyal RK. "Efficacy of E. littorale in type 2 diabetic patients". Phytotherapy Research 18 (2004): 233-235.

16. Liang HL., et al. "Decaffeination of fresh green tea leaf (Camellia sinensis) by hot water treatment". Food Chemistry 101 (2007): 1451-145.

17. G Charpentier. Diabetes/Metabolism Research and Reviews 18 (2002): S70.

18. Pari L and Amarnath SM. "Antidiabetic effect of Boerhavia diffusa: effect on serum and tissue lipids in experimental diabetes". Journal of Medicinal Food 7 (2004): 472-476.

19. Saleem R., et al. "Hypotensive, hypoglycemic and toxicological studies on the flavonol C-glycoside shamimin from Bombax ceiba". Planta Medica 5 (1999): 331-334.

20. Gupta SS., et al. "Antidiabetic effect of Tinospora cordifolia. I. Effect on fasting blood sugar level, glucose tolerence and adrenaline induced hyperglycemia”. Indian Journal of Experimental Biology 55 (1967): 733-745.

Volume 5 Issue 12 December 2021

(C) All rights are reserved by $S$ Bhuvaneswari., et al. 